\title{
Evaluation of biomarkers for ecotoxicity assessment by dose-response dynamic models: Effects of nitrofurazone on antioxidant enzymes in the model ciliated protozoan Euplotes vannus
}

\author{
Yazhen Hong ${ }^{\mathrm{a}}$, Yalin Tan ${ }^{\mathrm{a}}$, Yang Meng ${ }^{\mathrm{a}}$, Hao Yang ${ }^{\mathrm{a}}$, Yu Zhang ${ }^{\mathrm{a}}$, Alan Warren ${ }^{\mathrm{b}}$, Jiqiu Li ${ }^{\mathrm{a}, *}$, \\ Xiaofeng Lin $^{a}$ \\ a Guangzhou Key Laboratory of Subtropical Biodiversity and Biomonitoring, South China Normal University, Guangzhou 510631, PR China \\ b Department of Life Sciences, Natural History Museum, Cromwell Road, London SW7 5BD, UK
}

\section{A R T I C L E I N F O}

\section{Keywords:}

Antioxidant enzymes

Aquaculture industry

Biomarker

Dynamic model

Model protozoan

Nitrofurazone

\begin{abstract}
A B S T R A C T
Understanding dose-responses is crucial for determining the utility of biomarkers in ecotoxicity assessment. Nitrofurazone is a broad-spectrum antibiotic that is widely used in the aquaculture industry in China despite its detrimental effects on ecosystems. Potential dose-response models were examined for the effect of nitrofurazone on two antioxidant enzymes, superoxide dismutase (SOD) and glutathione peroxidase (GPx), in the ciliated protozoan Euplotes vannus. This was achieved by measuring enzyme activity and gene expression profiling of SOD and GPx in ciliate cells exposed to nitrofurazone at doses ranging from 0 to $180 \mathrm{mg} \mathrm{l}^{-1}$ for $6 \mathrm{~h}, 12 \mathrm{~h}, 18 \mathrm{~h}$ and $24 \mathrm{~h}$. Dose-response dynamics were characterized by mathematical models. Results showed that: 1) doseresponse patterns differed significantly among the tested endpoints, nitrofurazone concentrations and durations of exposure; 2) GPx activity was the best candidate biomarker because of its linear dose-response relationship; 3) SOD activity and mRNA relative expression levels of GPX and SOD are also candidate biomarkers but their doseresponses were non-linear and therefore more difficult to interpret; 4) partitioning the dose-response dynamic model by piecewise function can help to clarify the relationships between biological endpoints. This study demonstrates the utility of dynamic model analysis and the potential of antioxidant enzymes, in particular GPx activity, as a candidate biomarkers for environmental monitoring and risk assessment of nitrofurazone in the aquaculture industry.
\end{abstract}

\section{Introduction}

Veterinary antibiotics are widely used in farmed-animal industries for prophylactic and therapeutic purposes, to promote growth, and to increase feeding efficiency (Chen et al., 2014; Puckowski et al., 2016). It is estimated, however, that $40-90 \%$ of the administered veterinary antibiotics are released into the environment in the form of parent compounds and/or their metabolites (Phillips et al., 2004; Kumar et al., 2005; Kemper, 2008). Furthermore, the abuse of antibiotics in intensive aquaculture has caused a range of environmental problems including antibiotic resistance and the appearance of ultra-virulent bacteria, which in turn necessitate the use of more antibiotics, further aggravating the deterioration of the environment (Tendencia and Peña, 2002; Qi et al., 2009; Dafale et al., 2016). Moreover, antibiotics not only affect bacteria but also can seriously impair non-target organisms, thus impacting on wider biological processes (Białk-Bielińska et al., 2011; Hassan et al., 2016). These problems increasingly affect community composition and ecosystem function in aquaculture ecosystems (Puckowski et al., 2016). There is therefore a growing need to monitor water quality and to evaluate the ecotoxicological risks of antibiotic use in the aquaculture industry (Vutukuru et al., 2007; Puckowski et al., 2016).

Biological assays have a number of advantages over chemical assays for monitoring water quality. These include the ability to reflect the bioavailability of toxicants, the effects of mixtures of toxic compounds, both known and unknown, on biota and the mechanisms by which the toxic compounds act (Hendriks et al., 1994; Van et al., 2010; He et al., 2012; Li et al., 2013; Hassan et al., 2016). Furthermore, the use of bioassays is well established at multinational (e.g. the EU OSPAR Coordinated Environmental Monitoring Program) and national (e.g. the UK National Marine Monitoring Program) levels (Hagger et al., 2006). Bioassays rely on the quantitative relationships between environmental stressors, including contaminant level and exposure time, and biomarker responses elicited in the target organisms (Mushak, 2013).

\footnotetext{
* Corresponding author.

E-mail address: lijiqiu@126.com (J. Li).
} 
There is, however, uncertainty over the precise nature of some of these relationships which is hampering the selection of ideal biomarkers and limiting the application of biological assays in practice (Li et al., 2014; Hong et al., 2015a, 2015b). These uncertainties are due to a combination of the complexity of biomarker responses, the properties of the contaminant and a lack of pragmatic methods for processing biomarker response patterns (Hong et al., 2015b; Vidal-Liñán et al., 2016). Recent advances in dynamic model analyses, particularly the development of dynamic models for estimating dose-responses, are addressing such methodological problems both by helping to reinterpret existing data and to generate novel predictive models (McCarty, 2013; Li et al., 2014; Hong et al., 2015a, 2015b).

Exposure of organisms to antibiotics can increase the generation of reactive oxygen species (ROS) leading to oxidative stress (Kohanski et al., 2007; Páez et al., 2011; Grant et al., 2012; Hong et al., 2015a, 2015b). Consequently, free radical-scavenging antioxidant enzymes, such as superoxide dismutase (SOD), catalase (CAT), and glutathione peroxidase (GPx), are being intensively studied due to their potential as biomarkers (Velisek et al., 2011; Stara et al., 2012). Both the activity and the gene expression of antioxidant enzymes are induced by increasing production of ROS and might therefore serve as indicators of oxidative stress toxicity (Winston and Giulio, 1991; Cossu et al., 1997; Hagger et al., 2006). In some cases the detoxification processes may be completed by the entire antioxidant defense system involving complicated interactive mechanisms among these antioxidant enzymes ( $\mathrm{Li}$ et al., 2013; Kaur and Kaur, 2015). Further complexities and uncertainties are caused by other factors such as dose-response, time-response, and interactions between the biological endpoints (Hagger et al., 2006; Li et al., 2013; Kaur and Kaur, 2015). With the development of intensive aquaculture practices the use of antibiotics, and consequently their concentration in the aquatic environment, is increasing. Thus, it is necessary to investigate the ecotoxicological effects of antibiotics in a greater concentration range than is usually present in the aquatic environment. Key questions that therefore arise include: 1) do higher concentrations of antibiotics affect the dose-response patterns of antioxidant enzymes in the same way as they do at lower concentrations? 2) do divergences exist in the response patterns between biological endpoints? 3) can a dynamic dose-response model be developed that takes account of these divergences?

Ciliated protozoa are important components of microbial food webs and play a crucial role in controlling the flux of materials and energy within ecosystems (Eccleston-Parry and Leadbeater, 1994). Due to their short life cycles, cosmopolitan distribution, and rapid response to environmental disturbance, ciliated protozoa are increasingly recognized as ideal indicator organisms for environmental impact assessment (Nilsson, 1989). Montagnes et al. (2012) reviewed the utility of protozoa as model organisms in a wide range of fields of study including ecology, ecotoxicology and physiology, and concluded that they have numerous advantages. Ciliated protozoa in particular are increasingly used as model organisms in bioassays. The freshwater ciliate Tetrahymena thermophila, for example, has been used as a model organism to investigate the ecotoxicity of nanoparticles of $\mathrm{CuO}$ and $\mathrm{ZnO}$ in natural water (Blinova et al., 2010) and ecotoxicological assessments of biochar, a type of charcoal commonly used for soil amendment (Oleszczuk et al., 2013). There have also been several recent studies using marine ciliates to evaluate the ecotoxicity of various aquatic pollutants (Zhou et al., 2011; Gomiero et al., 2012; Li et al., 2014; Hong et al., 2015a, 2015b).

Nitrofurazone is a broad-spectrum antibiotic whose use in aquaculture is prohibited in many countries. Nevertheless, it is still widely used because of its low cost and efficacy (Vlastos et al., 2010; Du et al., 2014). In two recent studies, we have demonstrated the potential of the marine ciliate Euplotes vannus as a model organism for evaluating antioxidant enzymes as biomarkers of nitrofurazone-induced ecotoxicity at low (0-24 $\mathrm{mg}^{-1}$ ) concentrations of exposure (Li et al., 2014; Hong et al., 2015a, 2015b). In the present study, E. vannus was used to investigate the ecotoxicological effects of exposure to nitrofurazone in a greater range of concentrations $\left(0-180 \mathrm{mg} \mathrm{l}^{-1}\right)$. Specifically, activity and gene expression of the antioxidant enzymes SOD and GPx were used as biomarkers of nitrofurazone ecotoxicity. The main aims were to develop a dose-response dynamic model for evaluating the potential of these biomarkers for risk assessment of nitrofurazone in aquatic ecosystems and to improve their utility for inclusion in routine monitoring protocols.

\section{Materials and methods}

\subsection{Nitrofurazone}

Nitrofurazone (5-nitro-2-furfural semicarbazone) was obtained from Sigma-Aldrich Shanghai Trading Co., Ltd., Shanghai, China (CAS No.: 59870). A stock solution (200 $\mathrm{mg}^{-1}$ ) of nitrofurazone was prepared with sterile artificial marine water (AMW) consisting of $28 \mathrm{~g} \mathrm{NaCl}, 0.8 \mathrm{~g}$ $\mathrm{KCl}, 5 \mathrm{~g} \mathrm{MgCl}_{2} \cdot 6 \mathrm{H}_{2} \mathrm{O}, 1.2 \mathrm{~g} \mathrm{CaCl}_{2}$ and $1000 \mathrm{ml}$ distilled water ( $\mathrm{pH} 8.2$, salinity $30 \%$ ). The stock solution was diluted with sterile AMW to give appropriate concentrations of nitrofurazone in toxicity exposure experiments (Li et al., 2014; Hong et al., 2015b).

\subsection{Organisms and media}

The marine ciliate Euplotes vannus, identified by a combination of morphological and molecular information (Chen and Song, 2002), was obtained from the Laboratory of Protozoology Ocean University of China, Qingdao, China. Clonal cultures of E. vannus were established and maintained in Petri dishes with sterilized AMW (prepared as described above) at $25^{\circ} \mathrm{C}$. Rice grains were added to each Petri dish to enrich the natural bacterial populations as a food source for $E$. vannus.

\subsection{Toxicity exposure of nitrofurazone}

Cells of E. vannus in logarithmic growth phase were exposed to nitrofurazone at concentrations of $0,0.5,1.5,3,6,12,24,36,42,48,54$, $66,90,138$, and $180 \mathrm{mg} \mathrm{l}^{-1}$. In each case, durations of exposure were $6 \mathrm{~h}, 12 \mathrm{~h}, 18 \mathrm{~h}$, and $24 \mathrm{~h}$. Treatments were performed in $50 \mathrm{ml}$ sterilized conical flasks, each containing $20 \mathrm{ml}$ of solution, sealed with airpermeable film and incubated at $25^{\circ} \mathrm{C}$ in the dark. The density of ciliate cells in each solution was approximately $4 \times 10^{3}$ ind. $\mathrm{ml}^{-1}$. The ciliates were not fed throughout the experiment. At the end of the exposure period, ciliate cells were washed gently with sterilized AMW and incubated for $12 \mathrm{~h}$ in the presence of $10 \mathrm{mg} \mathrm{ml}^{-1}$ lysozyme. They were then centrifuged at $956 \mathrm{~g}$ at $4{ }^{\circ} \mathrm{C}$ for $3 \mathrm{~min}$ and washed gently with sterilized AMW. This purification procedure was repeated three times. After purification, cells were lysed for protein and RNA extraction.

\subsection{Determination of antioxidant enzyme activity}

Cells were lysed in lysis buffer, 1\% $100 \mathrm{mM}$ Phenylmethanesulfonyl fluoride (PMSF, purity > 99\%; Beyotime Co., China) for Western Blot and the immunoprecipitation of proteins (IP). The samples were kept on ice during the pre-processing procedure. Cells in lysed buffer were homogenized on ice using a homogenizer (Sonifier cell disrupter, UH$100 \mathrm{~A}$, Tianjin). Total cell homogenates were centrifuged at $20,000 \mathrm{~g}$ for $10 \mathrm{~min}$ at $4{ }^{\circ} \mathrm{C}$ and the supernatant was used to determine the antioxidant enzyme activity. SOD activity was measured by the ferricytochrome c method (McCord and Fridovich, 1969). Briefly, xanthine: xanthine oxidase was used as a source of superoxide radicals and absorption values were monitored at $550 \mathrm{~nm}$. One unit of SOD activity is defined as the amount of enzyme required to inhibit cytochrome $\mathrm{c}$ reduction by $50 \%$. Enzyme activity is expressed as units per milligram protein. GPx activity was determined by the rate of NADPH oxidation in a coupled reaction with glutathione reductase and measured by absorbance in a micro-plate reader at $412 \mathrm{~nm}$ (Lawrence and Burk, 1976). 
The amount of enzyme required to consume $1 \mu \mathrm{mol}$ glutathione (GSH) in $1 \mathrm{~min}$ was defined as one unit of GPx. This activity was also expressed as units per milligram protein. The protein level was determined by the Bradford method (Bradford, 1976). Briefly, bovine serum albumin was used as a standard and absorbance was recorded at $595 \mathrm{~nm}$. All measurements were performed using a model 680 microplate reader (Bio-Rad, USA).

\subsection{Quantitative analyses of antioxidant enzyme gene expression}

The methods for total RNA and gene expression analyses were described in detail by Hong et al. (2015b). To test the relative gene expression level of antioxidant enzymes, total RNA from the ciliates was extracted, further treated with RQ1 RNase-Free DNase (Promega, Madison, USA), and then reverse-transcribed into complementary DNA (cDNA) using the M-MLV RTase cDNA Synthesis Kit (TaKaRa, Dalian, Japan). The purity of RNA in the samples was determined by measuring the ratio of absorbance at 260, 280 and $230 \mathrm{~nm}$ (i.e., A260: A280 and A260: A230), using a Nano Drop ND-1000 spectrophotometer. In addition, the integrity of $18 \mathrm{~S}$ and $28 \mathrm{~S}$ rRNA bands was tested by $1 \%$ agarose gel electrophoresis. Manganese superoxide dismutase (MnSOD) (GenBank accession no. KJ619484) and GPx (GenBank accession no. KF049698) of $E$. vannus were used as target genes. The $\alpha$-tubulin gene of E. vannus (GenBank accession no. Z11769) was used as an internal control. Based on preliminary findings that the amplicon efficiencies of the target and internal control genes were generally equal (data not shown), the $\alpha$-tubulin gene of E. vannus (GenBank accession no. Z11769) was used as a reference gene.

Two MnSOD-specific primers (SOD-1 and SOD-2) were used to amplify a 104-bp fragment of MnSOD (Hong et al., 2015b). Primers GPx-1 and GPx-2 were used to amplify a 111-bp fragment of GPx (Hong et al., 2015b). Primers tubulin-1 and tubulin-2 were used to amplify a 122-bp fragment of $\alpha$-tubulin as the internal control for quantitative RT-PCR (Li et al., 2014). To study mRNA relative expression of MnSOD and GPx in ciliates treated with nitrofurazone at different doses and durations of exposure, real-time PCR was performed on an ABI 7500 (Applied Biosystems, USA). The PCR reaction was performed as previously described (Hong et al., 2015b). A dissolution curve was examined to ensure that each PCR product was unique. The relative expression levels of target genes were calculated using the $2^{-\Delta \Delta \mathrm{CT}}$ method (Livak and Schmittgen, 2001).

\subsection{Statistical analyses}

Dose-response models were established by SigmaPlot software (Version 9) to characterize the dose-response dynamics (for details of methods, see Li et al., 2014). The Akaike information criterion (AIC) was used to measure the relative quality of statistical models for a given set of data (Akaike, 1987). Adjusted $\mathrm{R}^{2}$-values for the responses, standard errors of the estimates were determined (SIGMAPLOT), to indicate their goodness of fit. Paired $t$-tests were used to determine significant differences in biological responses between discrete exposure durations by using SPSS software (version 19.0 for Windows). To analyze the relationships between biological responses and nitrofurazone concentrations, as well as possible correlations between enzyme activities and relative gene expression levels, Pearson's correlation analysis was performed using SPSS software (version 19.0 for Windows). All tests used a statistical significance level of $P<0.05$.

\section{Results}

\subsection{SOD activity and dose-response dynamics}

During each of the four periods of exposure, SOD activity rose to a peak and then declined with increasing concentration of nitrofurazone (Fig. 1). In each case, the dose-response graph comprised two roughly
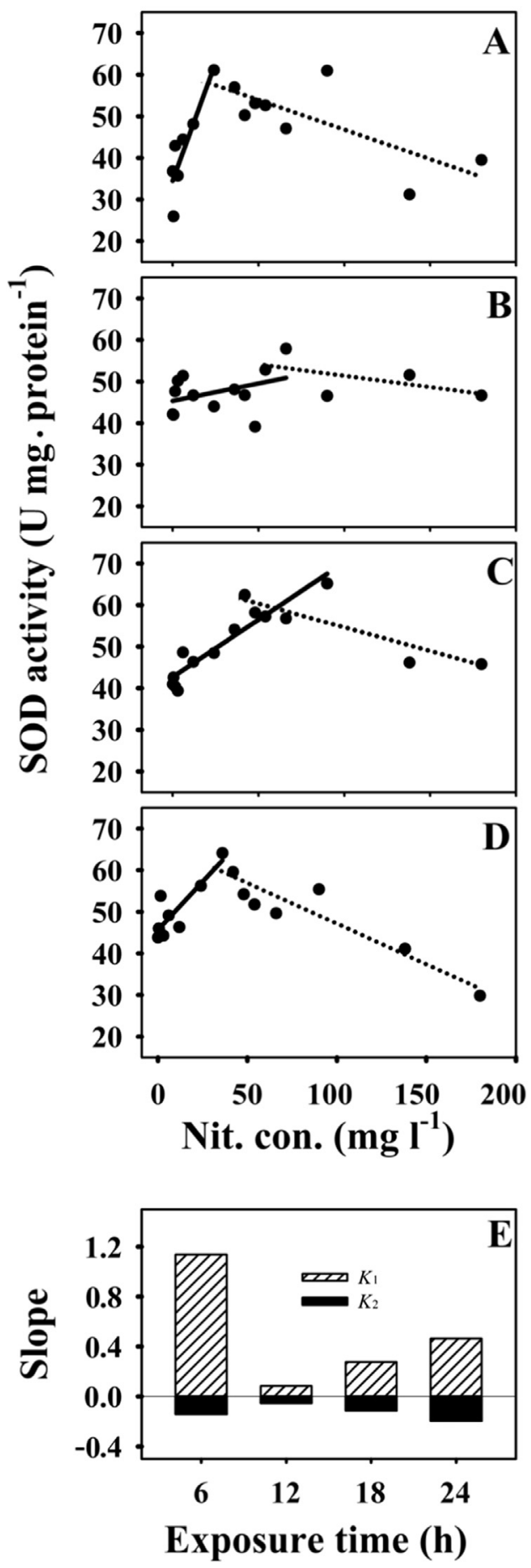

Fig. 1. Dose-response dynamics for enzyme activity of superoxide dismutase (SOD) in Euplotes vannus exposed to different concentrations of nitrofurazone for exposure durations ranging from $6 \mathrm{~h}$ to $24 \mathrm{~h}$. A, B, C, D: exposure durations of $6 \mathrm{~h}, 12 \mathrm{~h}, 18 \mathrm{~h}$, and $24 \mathrm{~h}$, respectively. E: the slopes of straight lines from A, B, C, D. Continuous lines are the best-fit to the data in the figures following equations in Table S1, respectively.

straight lines, one pre-peak and one post-peak (Fig. 1, A, B, C, D). When data of SOD activity were plotted against exposure time, the slopes of the pre-peak $\left(K_{1}\right)$ and post-peak $\left(K_{2}\right)$ lines were U-shaped and inverted U-shaped curves, respectively (Fig. 1, E).

\subsection{GPx activity and dose-response dynamics}

GPx activity increased markedly with increasing nitrofurazone 

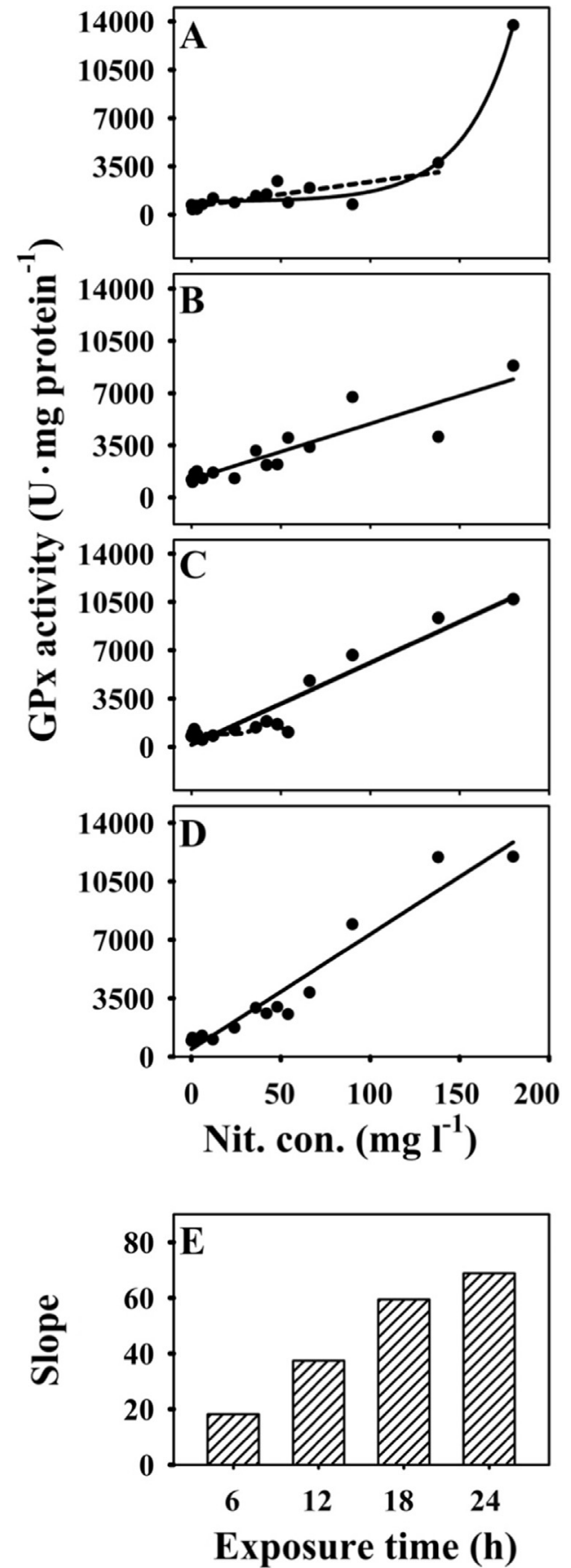

Fig. 2. Dose-response dynamics for enzyme activity of glutathione peroxidase (GPx) in Euplotes vannus exposed to different concentrations of nitrofurazone for exposure durations ranging from $6 \mathrm{~h}$ to $24 \mathrm{~h}$. A, B, C, D: exposure durations of $6 \mathrm{~h}, 12 \mathrm{~h}, 18 \mathrm{~h}$, and $24 \mathrm{~h}$, respectively. E: the slopes of straight lines from A, B, C, D. Continuous lines are the best-fit to the data in the figures following equations in Table S2, respectively.

concentration (Fig. 2). At exposure duration of $6 \mathrm{~h}$, GPx activity increased linearly at lower nitrofurazone concentrations and exponentially at higher nitrofurazone concentrations (Fig. 2, A). At exposure durations of $12 \mathrm{~h}, 18 \mathrm{~h}$, and $24 \mathrm{~h}, \mathrm{GPx}$ activity increased linearly with increasing nitrofurazone concentration $(P<0.001$; Fig. $2, \mathrm{~B}, \mathrm{C}, \mathrm{D})$. Furthermore, the slopes of the lines $(K)$ increased almost linearly with increasing durations of exposure from $6 \mathrm{~h}$ to $24 \mathrm{~h}$ (Fig. 2, E).
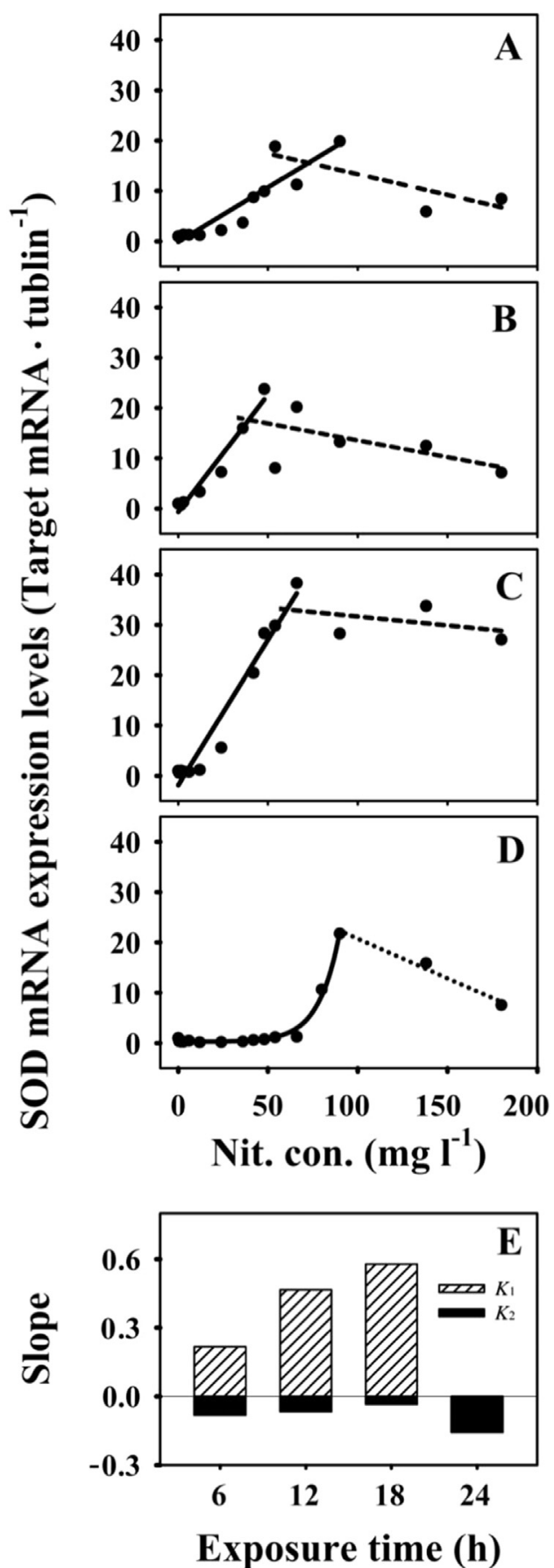

Fig. 3. Dose-response dynamics for mRNA relative expression levels of superoxide dismutase (SOD) in Euplotes vannus exposed to different concentrations of nitrofurazone for exposure durations ranging from $6 \mathrm{~h}$ to $24 \mathrm{~h}$. A, B, C, D: exposure durations of $6 \mathrm{~h}, 12 \mathrm{~h}$, $18 \mathrm{~h}$, and $24 \mathrm{~h}$, respectively. E: the slopes of straight lines from A, B, C, D. Continuous lines are the best-fit to the data in the figures following equations in Table S3, respectively.

\subsection{Relative levels of expression of SOD $m R N A$ and dose-response dynamics}

The relative levels of expression of SOD mRNA increased at lower nitrofurazone concentrations to a peak and then decreased at higher concentrations (Fig. 3). At exposure durations of $6 \mathrm{~h}, 12 \mathrm{~h}$, and $18 \mathrm{~h}$, each dose-response graph comprised two roughly straight lines, one pre-peak and one post-peak (Fig. 3, A, B, C). With increasing exposure durations, the slopes of the dose-response lines $\left(K_{1}\right)$ increased pre-peak whereas the absolute values of slopes decreased post-peak (Fig. 3, E). At 

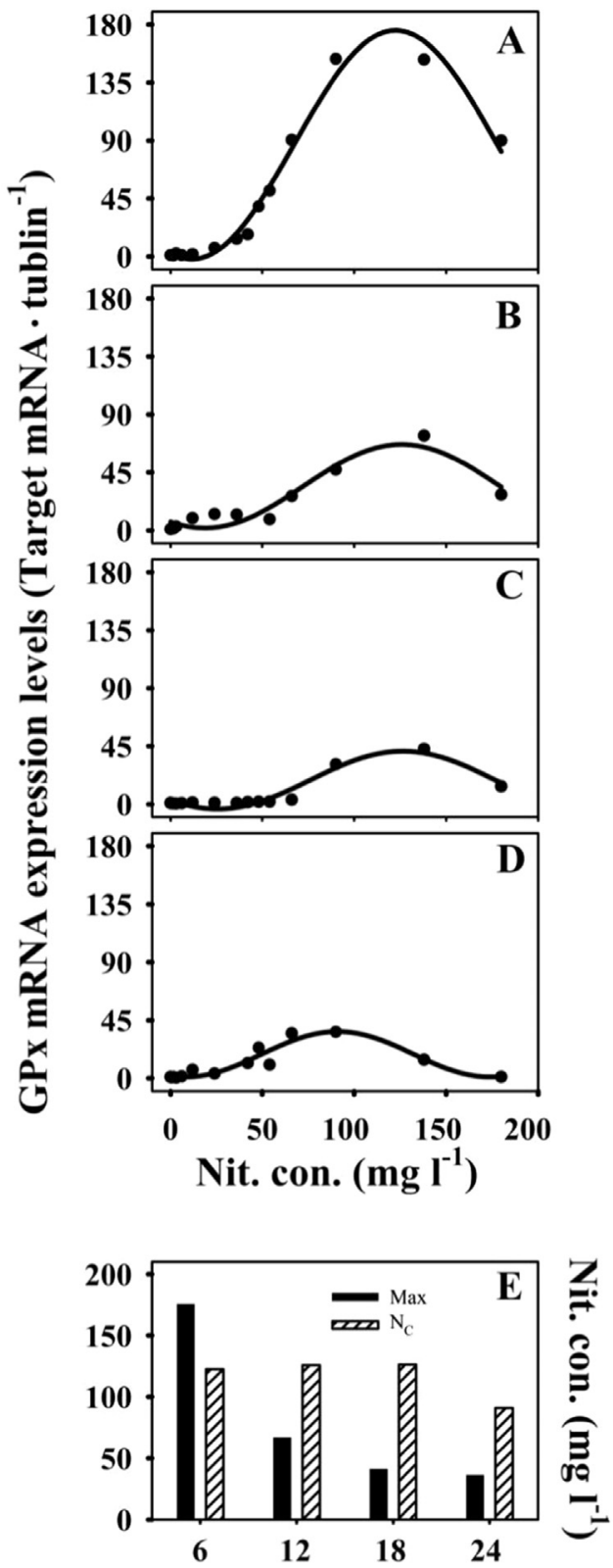

Exposure time (h)

Fig. 4. Dose-response dynamics for mRNA relative expression levels of glutathione peroxidase (GPx) in Euplotes vannus exposed to different concentrations of nitrofurazone for exposure durations ranging from $6 \mathrm{~h}$ to $24 \mathrm{~h}$. A, B, C, D: exposure durations of $6 \mathrm{~h}, 12 \mathrm{~h}$, $18 \mathrm{~h}$, and $24 \mathrm{~h}$, respectively. E: the Max and $\mathrm{N}_{\mathrm{c}}$ in the dose-response curves from A, B, C, D. Max is the maximum values of mRNA relative expression levels of GPx and $N_{c}$ is the nitrofurazone concentration for Max. Continuous lines are the best-fit to the data in the figures following equations in Table S4, respectively.

the $24 \mathrm{~h}$ exposure, relative expression levels of SOD mRNA increased exponentially to a peak and then decreased linearly with increasing nitrofurazone concentration (Fig. 3, D).

\subsection{Relative expression of GPx mRNA and dose-response dynamics}

GPx mRNA expression relative to nitrofurazone concentration presented a typical bell-shaped curve with gene expression increasing to a peak before declining at higher concentrations of nitrofurazone (Fig. 4, A, B, C, D). Both the peak value (Max) of relative expression of mRNA, and the nitrofurazone concentration $\left(\mathrm{N}_{\mathrm{c}}\right)$ at which the peak occurred, decreased with increasing exposure time (Fig. 4, E).
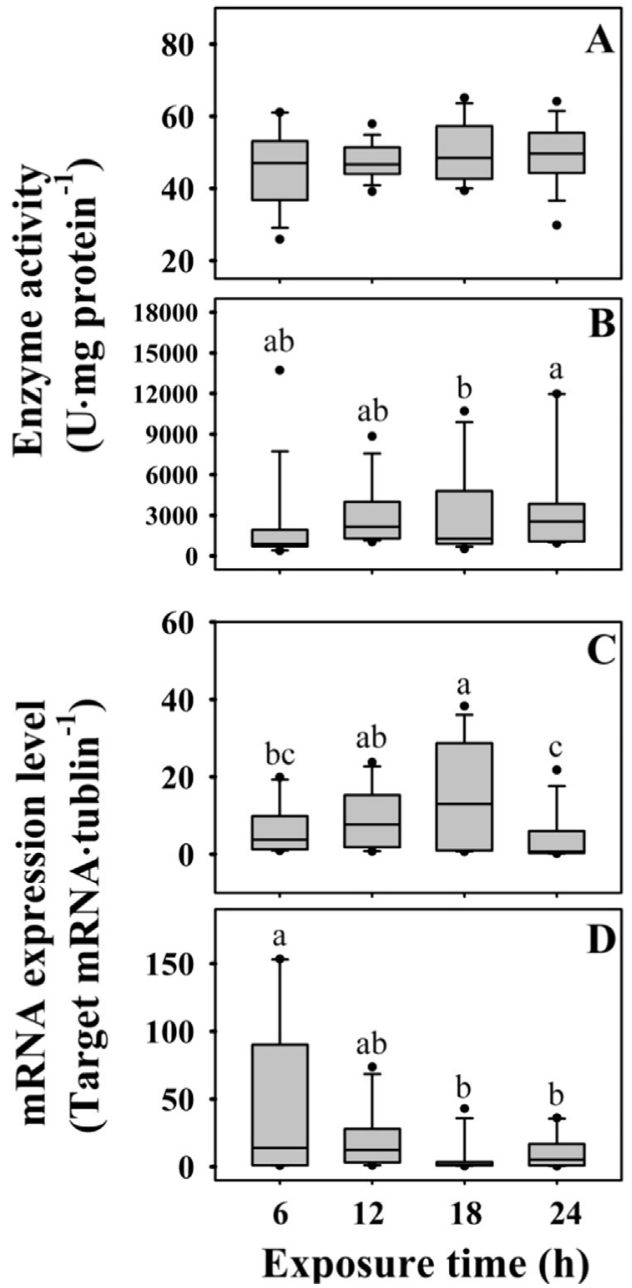

Fig. 5. Box-chart analyses of antioxidant enzyme activity and mRNA relative expression level. A: Activities of superoxide dismutase (SOD); B: Activities of glutathione peroxidase (GPx); C: mRNA relative expression levels of SOD; D: mRNA relative expression levels of GPx.

\subsection{Box-chart analyses of antioxidant enzyme activity and $m R N A$} expression

The statistical distribution patterns of between-group data, and the variations of within-group data, are illustrated by box-chart analyses (Fig. 5). SOD activities at each duration of exposure had a relatively large box size compared to the whiskers extending vertically from the boxes (Fig. 5, A). T-test analyses showed no significant differences between the groups at different durations of exposure $(P>0.05)$. By contrast, significant differences in GPx activities were found at different durations of exposure (Fig. 5, B; $P<0.05$ ). Compared to antioxidant enzyme activities, mRNA gene expression presented significantly different distribution patterns at different durations of exposure. SOD mRNA expression presented no distinct variation, however, the box sizes first increased and then decreased after peaking at an exposure duration of $18 \mathrm{~h}$ (Fig. 5, C). The box sizes and whiskers in GPx mRNA expression generally decreased with longer durations of exposure (Fig. 5, D; $P<0.05$ ). In brief, these results indicated that dose-responses were influenced by a combination of nitrofurazone concentration and duration of exposure.

3.6. Correlations between antioxidant enzyme activity, mRNA expression, and nitrofurazone dose

Correlations between antioxidant enzyme activity, mRNA 
Table 1

Correlation between antioxidant enzymes (activity, mRNA expression level), nitrofurazone concentration and duration of exposure using the Pearson's correlation coefficient.

\begin{tabular}{|c|c|c|c|c|}
\hline \multirow[t]{2}{*}{ Variables } & \multicolumn{4}{|c|}{ Exposure Duration } \\
\hline & $6 \mathrm{~h}$ & $12 \mathrm{~h}$ & $18 \mathrm{~h}$ & $24 \mathrm{~h}$ \\
\hline SOD activity $\times$ Nitrofurazone Con. & -0.004 & 0.215 & 0.277 & -0.458 \\
\hline $\begin{array}{l}\text { SOD mRNA expression } \times \\
\text { Nitrofurazone Con. }\end{array}$ & 0.513 & 0.442 & $0.766^{* *}$ & $0.881 * *$ \\
\hline SOD activity $\times$ mRNA expression & 0.477 & 0.102 & $0.678^{* *}$ & $-0.544 *$ \\
\hline GPx activity $\times$ Nitrofurazone Con. & $0.816^{* *}$ & $0.896 * *$ & $0.954 * *$ & $0.968^{* *}$ \\
\hline $\begin{array}{l}\text { GPx mRNA expression } \times \\
\text { Nitrofurazone Con. }\end{array}$ & $0.828 * *$ & $0.760 * *$ & $0.721 * *$ & 0.344 \\
\hline GPx activity $\times$ mRNA expression & 0.391 & 0.547 & $0.806^{* *}$ & 0.317 \\
\hline
\end{tabular}

expression, and nitrofurazone concentration varied according to the durations of exposure to nitrofurazone (Table 1). SOD activity had no significant dose relationship $(P>0.05)$ whereas mRNA expression was significantly correlated with nitrofurazone concentration at $18 \mathrm{~h}$ and $24 \mathrm{~h}$ of exposure $(P<0.01)$. SOD enzyme activity was, however, positively correlated with mRNA expression at $18 \mathrm{~h}$ exposure to nitrofurazone $(P<0.01)$ but negatively correlated at $24 \mathrm{~h}$ exposure $(P<0.01)$. GPx enzyme activity was positively correlated with nitrofurazone concentration for all four durations of exposure $(P<0.01)$. GPx mRNA expression was positively correlated with nitrofurazone concentration from $6 \mathrm{~h}$ to $18 \mathrm{~h}$ exposure $(P<0.01)$, but was not significantly correlated at $24 \mathrm{~h}$ exposure $(P>0.05)$. GPx mRNA expression was significantly correlated with enzyme activity at $18 \mathrm{~h}$ exposure only. Results of correlation analyses indicated that the correlation depended on enzyme properties, biological endpoint levels, and duration of exposure.

\section{Discussion}

The broad-spectrum antibiotic nitrofurazone has been widely used in human and veterinary medicine (Reynolds, 1982). The mechanism by which it inactivates bacteria is based on nitrofurazone metabolites causing oxidative DNA damage by generating reactive oxygen species (ROS) through their interaction with copper (Hiraku et al., 2004). As mentioned above, nitrofurazone is still widely used in aquaculture in many countries because of its low cost and efficiency (Du et al., 2014; Vlastos et al., 2010). Furthermore, with the drastic development of intensive aquaculture, the amount of antibiotics accumulating in aquaculture environments is increasing (Puckowski et al., 2016). Although the concentrations of nitrofurazone used in the present study exceeded those typically found in aquaculture waters (Yanong, 2003), the dose-response patterns will nevertheless provide insights for verifying the existing model as well as predicting future ecotoxicity trends.

In aerobic organisms, antioxidant enzymes are crucial components of defense systems that prevent the uncontrolled formation of free radicals and activated oxygen species (Doyen et al., 2006). Among the central antioxidant enzymes, SOD catalyzes the conversion of superoxide anions, generated in peroxisomes and mitochondria, to water and hydrogen peroxide (Velisek et al., 2011; Stara et al., 2012). Furthermore, its activity reflects levels of oxidative stress in cells (Hu et al., 2016). GPx is another important endogenous antioxidant enzyme and catalyzes the conversion of peroxides to water and oxygen with GSH as the electron donor (Kutlu and Susuz, 2004; Drevet, 2006; Liu et al., 2010). Antioxidant enzyme activity and gene expression have been used as sensitive biomarkers for monitoring environmental stress (Cossu et al., 1997; Hagger et al., 2006; Kerambrun et al., 2016). It has also been reported that superoxide anion radicals and hydrogen peroxide are formed during the reductive metabolism of nitrofurazone in rat brain tissue (Ghersi-Egea et al., 1998). The present study shows that levels of both activity and mRNA expression of the antioxidant enzymes SOD and GPx varied with nitrofurazone dose, confirming their potential as biomarkers for ecotoxicity as suggested previously (Li et al., 2014; Hong et al., 2015b).

Under normal physiological conditions, SOD levels maintain a dynamic balance and meet the need of the organism to eliminate superoxide anions (Hu et al., 2016). The balance between the formation and removal of superoxide anions can, however, easily be disrupted by stress (Liu et al., 2011). In this study, SOD enzyme activity in E. vannus exposed to increasing concentrations of nitrofurazone rose to a peak and then declined (Fig. 1). These findings suggest that E. vannus suffered nitrofurazone-induced oxidative stress, the level of stress being dependent upon both the concentration and the duration of exposure to nitrofurazone. In agreement with our previous study, SOD activity rose in E. vannus cells exposed to lower concentrations of nitrofurazone (0-30 $\mathrm{mg}^{-1}$ ) for durations ranging from $6 \mathrm{~h}$ to $24 \mathrm{~h}$ (Hong et al., 2015b). The effects of higher concentrations of nitrofurazone on antioxidant enzymes in ciliated protozoa have been rarely reported. However, it has been suggested that SOD activity can be inactivated by excessive hydrogen peroxide (Modesto and Martinez, 2010). Observations that lower concentrations of contaminants stimulate SOD activity while higher concentrations suppress SOD activity have been reported in other organisms, e.g. crucian carp (Carassius auratus) exposed to hexavalent chromium (Li et al., 2013) and phthalates (Zheng et al., 2013), and the snail (Cantareus apertus) exposed to carbamate pesticide (Leomanni et al., 2015). Correlation analyses showed no significant dose-dependent relationship in SOD activity in $E$. vannus $(P>0.05)$; SOD activity presented a non-linear dose-response pattern with increasing nitrofurazone concentrations. Moreover, the results of boxchart analyses indicated that SOD activity varied slightly with either nitrofurazone concentration or duration of exposure. In particular, no significant differences were detected between cells exposed to nitrofurazone for different durations ( $t$-test, $P>0.05$ ). These findings suggest that the impact of nitrofurazone dose on SOD activity was insignificant and that SOD activity is therefore not a suitable biomarker to evaluate nitrofurazone-induced ecotoxicity in E. vannus.

In contrast to SOD activity, GPx activity in E. vannus cells presented a linear dose-response pattern, with activity increasing as the nitrofurazone concentration increased $(P<0.001$; Fig. $2, \mathrm{~B}, \mathrm{C}, \mathrm{D})$. This is consistent with the findings of Hong et al. (2015b) who investigated $\mathrm{GPx}$ activity in $E$. vannus at lower concentrations of nitrofurazone $\left(0-30 \mathrm{mg}^{-1}\right)$ for the same durations of exposure. In the dose-response plots, the slopes of the straight lines $(K)$ generally increased linearly with increasing durations of exposure from $6 \mathrm{~h}$ to $24 \mathrm{~h}$ (Fig. 2, E). Results of box-chart analyses indicated that GPx activity varied significantly with both nitrofurazone concentration and duration of exposure ( $t$-test, $P<0.05$ ). Additionally, GPx activity was significantly positively correlated with nitrofurazone concentration $(P<0.05)$. Consequently, it was concluded that GPx activity is a candidate biomarker for the evaluation of nitrofurazone-induced ecotoxicity in $E$. vannus.

Gene expression profiling based on mRNA is a useful supplement for enzyme activity detection and has been used to identify biomarkers of toxicity of potentially hazardous contaminants (Brulle et al., 2010; Chen et al., 2011; Hu et al., 2016). In the present study, $t$-test and boxchart analyses demonstrated that gene expression profiling of the antioxidant enzymes SOD and GPx was significantly influenced by both the concentration of nitrofurazone and the duration of exposure (Fig. 5). Relative expression levels of SOD mRNA increased to a peak and then decreased with increasing concentrations of nitrofurazone (Fig. 3). In a previous study, elevated levels of mRNA expression for SOD were also observed in E. vannus exposed to a lower range of concentrations of nitrofurazone $\left(0-30 \mathrm{mg} \mathrm{l}^{-1}\right)$ for the same durations of exposure (Hong et al., 2015b). Similar results have been reported by $\mathrm{Hu}$ et al. (2016) who investigated gene expression of SOD mRNA in the earthworm (Eisenia fetida) after 14 days repetitive exposure to $\mathrm{Pb}$ and to the brominated flame retardant BDE209. There have also been reports on contaminant-induced down-regulation of antioxidant genes in 
various organisms including Javanese medaka (Oryzias javanicus) exposed to heavy metals (Woo et al., 2009) and Eisenia fetida exposed to BDE209 and Pb (Hu et al., 2016). Nitrofurazone in high concentrations has thus been linked to oxidative stress, probably as a result of decreased expression of antioxidant mRNA genes (Ghersi-Egea et al., 1998). In the case of SOD mRNA, the slopes of the linear dose-response patterns at exposure durations of $6 \mathrm{~h}, 12 \mathrm{~h}$, and $18 \mathrm{~h}$ significantly increased at lower concentrations and decreased at higher concentrations of nitrofurazone. However, the dose-response pattern at $24 \mathrm{~h}$ exposure deviated from the above trend. This suggests that SOD mRNA expression can be used as a biomarker under defined conditions of nitrofurazone concentration and duration of exposure. For example, when nitrofurazone concentration is less than $50 \mathrm{mg} \mathrm{l}^{-1}$ and exposure duration is less than $18 \mathrm{~h}$, toxicological effects of nitrofurazone can be assessed by SOD mRNA expression in E. vannus.

GPx mRNA expression presented a typical bell-shaped curve with increasing concentrations of nitrofurazone (Fig. 4). Both the peak value (Max) of mRNA expression and the equivalent nitrofurazone concentrations $\left(\mathrm{N}_{\mathrm{c}}\right)$ decreased with increasing durations of exposure (Fig. 4, E). Deng et al. (2012) proposed that the piecewise function can be used for fitting the biphasic dose-response curves obtained from chronic toxicity assays. Therefore, based on Max and $\mathrm{N}_{\mathrm{c}}$, each biphasic dose-response curve of GPx mRNA expression can be divided into two monomial curves by piecewise function, which will be more operable in practice. In agreement with previous observations (Calabrese and Baldwin, 2001), both biphasic and linear dose-response relationships are found in the test biological responses to nitrofurazone. Moreover, whether the biological responses are non- monotonic or monotonic partly depends on the concentration range of the test contaminant (Calabrese and Baldwin, 2001). Therefore, the problem that arises in biomarker use is that identical biological responses can be detected in test organisms at different concentrations of toxin. Such problems can largely be resolved by using piecewise function where the binomial curves are split into two monomial lines (Deng et al., 2012). A key challenge is how to evaluate the biological responses near the specific nitrofurazone dose where these responses peaked. In order to do this, biological responses for a narrower dose range of nitrofurazone that covers the above mentioned dose point should be investigated.

These findings demonstrate the potential of antioxidant enzymes, in particular GPx activity, as candidate biomarkers of nitrofurazone-induced toxicity. This does not mean, however, that GPx activity should be adopted uniquely. On the contrary, a battery of biomarkers coupled with chemical analyses should be used since this approach has been shown to provide the most comprehensive indication of ecosystem health (Solé, 2002; Hagger et al., 2006). By using a suite of biomarkers, a weight-of-evidence approach can be adopted thereby minimizing the influence of natural variation and allowing the accurate assessment of environmental quality (Hagger et al., 2006). Furthermore, a suite of biomarkers at different levels of biological organization facilitates a better understanding both of the biological processes affected and of the mechanism of toxicity, allowing bio-monitoring programs to be optimized. We therefore suggest that, within a battery of biomarkers, those presenting linear dose-response patterns should be given the greatest weight while others should be weighted less heavily.

Inconsistency of response patterns commonly occurs between biomarkers from different biological levels or components in identical systems, thus leading to equivocality in the correlations (Zheng et al., 2013; Hong et al., 2015b; Vidal-Liñán et al., 2016). Such phenomena occurred in the present study making the application of biomarkers more complicated. However, biological response patterns, particularly those that are non-linear, can be divided into several linear patterns by piecewise function based on specific parameters (e.g. Max and $\mathrm{N}_{\mathrm{c}}$ of GPx mRNA expression). This allows significant correlations, and doseresponse trends of the biomarkers, to be determined.

\section{Conclusions}

The results of the present study support the potential of the antioxidant enzymes SOD and GPx, and in particular levels of activity and mRNA gene expression, as candidate biomarkers of nitrofurazone-induced toxicity in aquaculture systems. Dynamic model analyses showed that GPx activity was the most reliable biomarker because of its linear dose-response. Other measures of antioxidant enzyme response, i.e. GPx mRNA expression and SOD activity, are useful but should be less heavily weighted as their responses are more complex. Furthermore, in order to optimize the utility of these biomarkers, we suggest that nonlinear dose-response data (e.g. Max and $\mathrm{N}_{\mathrm{c}}$ of GPx mRNA expression) should be divided by piecewise function based on the specific dose of nitrofurazone. However, the interactive effects between different antioxidant enzymes need to be further investigated during the biological process of detoxification in order to gain a better understanding of doseresponse dynamics.

\section{Conflict of interest}

None declared.

\section{Acknowledgements}

This work was supported by the National Natural Science Foundation of China (project nos. 41476128, 41576148, and 31430077) and in part by a grant from the Innovation Project of undergraduate of South China Normal University (no. 201610574023).

\section{Appendix A. Supporting information}

Supplementary data associated with this article can be found in the online version at http://dx.doi.org/10.1016/j.ecoenv.2017.06.069.

\section{References}

Akaike, H., 1987. Factor analysis and AIC. Psychometrika 52, 317-322.

Białk-Bielińska, A., Stolte, S., Arning, J., Uebers, U., Böschen, A., Stepnowski, P., 2011. Ecotoxicity evaluation of selected sulfonamides. Chemosphere 85, 928-933.

Blinova, I., Ivask, A., Heinlaan, M., Mortimer, M., Kahru, A., 2010. Ecotoxicity of nanoparticles of $\mathrm{CuO}$ and $\mathrm{ZnO}$ in natural water. Environ. Pollut. 158, 41-47.

Bradford, M.M., 1976. A rapid and sensitive method for the quantitation of microgram quantities of protein utilizing the principle of protein-dye binding. Anal. Biochem. 72, 248-254.

Brulle, F., Morgan, A.J., Cocquerelle, C., Vandenbulcke, F., 2010. Transcriptomic underpinning of toxicant-mediated physiological function alterations in three terrestrial invertebrate taxa: a review. Environ. Pollut. 158, 2793-2808.

Calabrese, E.J., Baldwin, L.A., 2001. The frequency of u-shaped dose responses in the toxicological literature. Toxicol. Sci. 62, 330-338.

Chen, C., Zhou, Q., Liu, S., Xiu, Z., 2011. Acute toxicity, biochemical and gene expression responses of the earthworm Eisenia fetida exposed to polycyclic musks. Chemosphere 83, 1147-1154.

Chen, G.X., He, W.W., Wang, Y., Zou, Y.D., Liang, J.B., Liao, X.D., Wu, Y.B., 2014. Effect of different oxytetracycline addition methods on its degradation behavior in soil. Sci. Total Environ. 479-480, 241-246.

Chen, Z., Song, W., 2002. Phylogenetic positions of Aspidisca steini and Euplotes vannus within the order Euplotida (Hypotrichia: Ciliophora) inferred from complete small subunit ribosomal RNA gene sequences. Acta Protozool. 41, 1-9.

Cossu, C., Doyotte, A., Jacquin, M.C., Babut, M., Exinger, A., Vasseur, P., 1997. Glutathione reductase, selenium-dependent glutathione peroxidase, glutathione levels, and lipid peroxidation in freshwater bivalves, Unio tumidus, as biomarkers of aquatic contamination in field studies. Ecotoxicol. Environ. Saf. 38, 122-131.

Dafale, N.A., Semwal, U.P., Rajput, R.K., Singh, G.N., 2016. Selection of appropriate analytical tools to determine the potency, microbial bioactivity and antibiotic resistances. J. Pharm. Anal. 6, 207-213.

Deng, Z.Q., Lin, Z.F., Zou, X.M., Yao, Z.F., Tian, D.Y., Wang, D.L., Yin, D.Q., 2012. Model of hormesis and its toxicity mechanism based on quorum sensing: a case study on the toxicity of sulfonamides to Photobacterium phosphoreum. Environ. Sci. Technol. 46, 7746-7754.

Doyen, P., Vasseur, P., Rodius, F., 2006. Identification, sequencing and expression of selenium-dependent glutathione peroxidase transcript in the freshwater bivalve Unio tumidus exposed to Aroclor 1254. Comp. Biochem. Physiol. C 144, 122-129.

Drevet, J.R., 2006. The antioxidant glutathione peroxidase family and spermatozoa: a complex story. Mol. Cell. Endocrinol. 250, 70-79.

Du, N.N., Chen, M.M., Sheng, L.Q., Chen, S.S., Xu, H.J., Liu, Z.D., Song, C.F., Qiao, R., 
2014. Determination of nitrofuran metabolites in shrimp by high performance liquid chromatography with fluorescence detection and liquid chromatography-tandem mass spectrometry using a new derivatization reagent. J. Chromatogr. A 1327, 90-96.

Eccleston-Parry, J.D., Leadbeater, B.S.C., 1994. A comparison of the growth kinetics of six marine heterotrophic nanoflagellates fed with one bacterial strain. Mar. Ecol. Prog. Ser. 105, 167-177.

Ghersi-Egea, J.F., Maupoil, V., Ray, D., Rochette, L., 1998. Electronic spin resonance detection of superoxide and hydroxyl radicals during the reductive metabolism of drugs by rat brain preparations and isolated cerebral microvessels. Free Radic. Biol. Med. 24, 1074-1081.

Gomiero, A., Sforzini, S., Dagnino, A., Nasci, C., Viarengo, A., 2012. The use of multiple endpoints to assess cellular responses to environmental contaminants in the interstitial marine ciliate Euplotes crassus. Aquat. Toxicol. 114-115, 206-216.

Grant, S.S., Kaufmann, B.B., Chand, N.S., Haseley, N., Hung, D.T., 2012. Eradication of bacterial persisters with antibiotic-generated hydroxyl radicals. Proc. Natl. Acad. Sci. USA 109, 12147-12152.

Grinten, E.V.D., Pikkemaat, M.G., Brandhof, E.J.V.D., Stroomberg, G.J., Kraak, M.H.S., 2010. Comparing the sensitivity of algal, cyanobacterial and bacterial bioassays to different groups of antibiotics. Chemosphere 80, 1-6.

Hagger, J.A., Jones, M.B., Leonard, D.P., Owen, R., Galloway, T.S., 2006. Biomarkers and integrated environmental risk assessment: are there more questions than answers? Integr. Environ. Assess. 2, 312-329.

Hassan, S.H.A., Ginkel, S.W.V., Hussein, M.A.M., Abskharon, R., Oh, S.E., 2016. Toxicity assessment using different bioassays and microbial biosensors. Environ. Int. 92-93, 106-118.

He, X.T., Nie, X.P., Yang, Y.F., Liu, X.Y., Pan, D.B., Cheng, Z., Liang, X.M., 2012. Multibiomarker responses in fishes from two typical marine aquaculture regions of South China. Mar. Pollut. Bull. 64, 2317-2324.

Hendriks, A.J., Maas-Diepeveen, J.L., Noordsij, A., Van der Gaag, M.A., 1994. Monitoring response of XAD-concentrated water in the Rhine delta: a major part of the toxic compounds remains unidentified. Water Res. 28, 581-598.

Hiraku, Y., Sekine, A., Nabeshi, H., Midorikawa, K., Murata, M., Kumagai, Y., Kawanishi, S., 2004. Mechanism of carcinogenesis induced by a veterinary antimicrobial drug, nitrofurazone, via oxidative DNA damage and cell proliferation. Cancer Lett. 215, 141-150.

Hong, Y.Z., Lin, X.F., Cui, X.D., Zhou, L., Al-Rasheid, K.A.S., Li, J., 2015a. Comparative evaluation of genotoxicity induced by nitrofurazone in two ciliated protozoa by detecting DNA strand breaks and DNA-protein crosslinks. Ecol. Indic. 54, 153-160.

Hong, Y.Z., Liu, S.X., Lin, X.F., Li, J.Q., Yi, Z.Z., Al-Rasheid, K.A.S., 2015b. Recognizing the importance of exposure-dose-response dynamics for ecotoxicity assessment: nitrofurazone-induced antioxidase activity and mRNA expression in model protozoan Euplotes vannus. Environ. Sci. Pollut. Res. 22, 9544-9553.

Hu, S.Q., Zhang, W., Li, J., Lin, K.F., Ji, R., 2016. Antioxidant and gene expression responses of Eisenia fetida following repeated exposure to BDE209 and Pb in a soilearthworm system. Sci. Total Environ. 556, 163-168.

Kaur, S., Kaur, A., 2015. Variability in antioxidant/detoxification enzymes of Labeo rohita exposed to an azo dye, acid black (AB). Comp. Biochem. Phys. C 167, 108-116.

Kemper, N., 2008. Veterinary antibiotics in the aquatic and terrestrial environment. Ecol. Indic. 8, 1-13.

Kerambrun, E., Rioult, D., Delahaut, L., Evariste, L., Pain-Devin, S., Auffret, M., Geffard, A., David, E., 2016. Variations in gene expression levels in four European zebra mussel, Dreissena polymorpha, populations in relation to metal bioaccumulation: a field study. Ecotoxicol. Environ. Saf. 134, 53-63.

Kohanski, M.A., Dwyer, D.J., Hayete, B., Lawrence, C.A., Collins, J.J., 2007. A common mechanism of cellular death induced by bactericidal antibiotics. Cell 130, 797-810.

Kumar, K., Gupta, S.C., Baidoo, S.K., Chander, Y., Rosen, C.J., 2005. Antibiotic uptake by plants from soil fertilized with animal manure. J. Environ. Qual. 34, 2082-2085.

Kutlu, M., Susuz, F., 2004. Biochemical properties of glutathione peroxidase in Gammarus pulex. B. Environ. Contam. Toxicol. 73, 432-436.

Lawrence, R.A., Burk, R.F., 1976. Glutathione peroxidase activity in selenium-deficient rat liver. Biochem. Biophys. Res. Commun. 71, 952-958.

Leomanni, A., Schettino, T., Calisi, A., Gorbi, S., Mezzelani, M., Regoli, F., Lionetto, M.G., 2015. Antioxidant and oxidative stress related responses in the Mediterranean land snail Cantareus apertus exposed to the carbamate pesticide carbaryl. Comp. Biochem. Phys. C 168, 20-27.

Li, S., Anderson, T.A., Maul, J.D., Shrestha, B., Green, M.J., Cañas-Carrell, J.E., 2013. Comparative studies of multi-walled carbon nanotubes (MWNTs) and octadecyl $\left(\mathrm{C}_{18}\right)$ as sorbents in passive sampling devices for biomimetic uptake of polycyclic aromatic hydrocarbons (PAHs) from soils. Sci. Total Environ. 461-462, 560-567.

Li, J.Q., Zhou, L., Lin, X.F., Yi, Z.Z., Al-Rasheid, K.A.S., 2014. Characterizing dose-responses of catalase to nitrofurazone exposure in model ciliated protozoan Euplotes vannus for ecotoxicity assessment: enzyme activity and mRNA expression. Ecotoxicol.
Environ. Saf. 100, 294-302.

Liu, W.D., He, C.B., Li, W.J., Zhou, Z.C., Gao, X.G., Fu, L.Y., 2010. Discovery of host defence genes in the Japanese scallop Mizuhopecten yessoensis Jay by expressed sequence tag analysis of kidney tissue. Aquac. Res. 41, 1602-1613.

Liu, S., Zhou, Q., Wang, Y., 2011. Ecotoxicological responses of the earthworm Eisenid fetida exposed to soil contaminated with HHCB. Chemosphere 83, 1080-1086.

Livak, K.J., Schmittgen, T.D., 2001. Analysis of relative gene expression data using realtime quantitative PCR and the $2^{-\Delta \Delta \mathrm{C}}(\mathrm{T})$ method. Methods 25, 402-408.

McCarty, L.S., 2013. Are we in the dark ages of environmental toxicology? Regul. Toxicol. Pharm. 67, 321-324.

McCord, J.M., Fridovich, I., 1969. Superoxide dismutase: an enzymatic function for erythrocuprein (hemocuprein). J. Biol. Chem. 244, 6049-6055.

Modesto, K.A., Martinez, C.B.R., 2010. Roundup ${ }^{\circledast}$ causes oxidative stress in liver and inhibits acetylcholinesterase in muscle and brain of the fish Prochilodus lineatus. Chemosphere 78, 294-299.

Montagnes, D., Roberts, E., Lukeš, J., Lowe, C., 2012. The rise of model protozoa. Trends Microbiol. 20, 184-191.

Mushak, P., 2013. Limits to chemical hormesis as a dose-response model in health risk assessment. Sci. Total Environ. 443, 643-649.

Nilsson, J.R., 1989. Tetrahymena in cytotoxicology: with special reference to effects of heavy metals and selected drugs. Eur. J. Protistol. 25, 2-25.

Oleszczuk, P., Jośko, I., Kuśmierz, M., 2013. Biochar properties regarding to contaminants content and ecotoxicological assessment. J. Hazard. Mater. 260, 375-382.

Páez, P.L., Becerra, M.C., Albesa, I., 2011. Comparison of macromolecular oxidation by reactive oxygen species in three bacterial Genera exposed to different antibiotics. Cell Biochem. Biophys. 61, 467-472.

Phillips, I., Casewell, M., Cox, T., Groot, B.D., Frii, C., Jones, R., Nightingale, C., Preston, R., Waddell, J., 2004. Does the use of antibiotics in food animals pose a risk to human health? Acritical review of published data. J. Antimicrob. Chemother. 53, 28-52.

Puckowski, A., Mioduszewska, K., Łukaszewicz, P., Borecka, M., Caban, M., Maszkowska, J., Stepnowski, P., 2016. Bioaccumulation and analytics of pharmaceutical residues in the environment: a review. J. Pharm. Biomed. 127, 232-255.

Qi, Z.Z., Zhang, X.H., Boon, N., Bossier, P., 2009. Probiotics in aquaculture of China current state, problems and prospect. Aquaculture 290, 15-21.

Solé, M., Barceló, D., Porte, C., 2002. Seasonal variation of plasmatic and hepatic vitellogenin and EROD activity in carp, Cyprinus carpio, in relation to sewage treatment plants. Aquat. Toxicol. 60, 233-248.

Stara, A., Machova, J., Velisek, J., 2012. Effect of chronic exposure to simazine on oxidative stress and antioxidant response in common carp (Cyprinus carpio L.). Environ. Toxicol. Pharmacol. 33, 334-343.

Tendencia, E.A., Peña, L.D.D., 2002. Level and percentage recovery of resistance to oxytetracycline and oxolinic acid of bacteria from shrimp ponds. Aquaculture 213, $1-13$.

Velisek, J., Stara, A., Kolarova, Z., Svobodova, Z., 2011. Biochemical, physiological and morphological responses in common carp (Cyprinus carpio L.) after long-term exposure to terbutryn in real environmental concentration. Pestic. Biochem. Phys. 100, 305-313.

Vidal-Liñán, L., Bellas, J., Soriano, J.A., Concha-Graña, E., Muniategui, S., Beiras, R., 2016. Bioaccumulation of PCB-153 and effects on molecular biomarkers acetylcholinesterase, glutathione-S-transferase and glutathione peroxidase in Mytilus galloprovincialis mussels. Environ. Pollut. 214, 885-891.

Vlastos, D., Moshou, H., Epeoglou, K., 2010. Evaluation of genotoxic effects of semicarbazide on cultured human lymphocytes and rat bone marrow. Food Chem. Toxicol. 48, 209-214.

Vutukuru, S.S., Prabhath, N.A., Raghavender, M., Yerramilli, A., 2007. Effect of arsenic and chromium on the serum amino-transferases activity in Indian major carp, Labeo rohita. Int. J. Environ. Res. Pub. Heal. 4, 224-227.

Winston, G.W., Giulio, R.T.D., 1991. Prooxidant and antioxidant mechanisms in aquatic organisms. Aquat. Toxicol. 19, 137-161.

Woo, S., Yum, S., Park, H., Lee, T., Ryu, J., 2009. Effects of heavy metals on antioxidants and stress-responsive gene expression in Javanese medaka (Oryzias javanicus). Comp. Biochem. Phys. C 149, 289-299.

Yanong, R.P.E., 2003. Use of antibiotics in ornamental fish aquaculture. In: Institute of Food and Agricultural Sciences (Ed). Florida Cooperative Extension Service. One of a series from the department of fisheries and aquatic sciences, Circular84. University of Florida.

Zheng, Q., Feng, M.B., Dai, Y., 2013. Comparative antioxidant responses in liver of Carassius auratus exposed to phthalates: an integrated biomarker approach. Environ. Toxicol. Pharmacol. 36, 741-749.

Zhou, A.J., Liu, H.Q., Zhang, A.N., Wang, X.D., Zhang, H.Q., Wang, H.L., 2011. Effect of BDE-209 on glutathione system in Carassius auratus. Environ. Toxicol. Pharmacol. 32, 35-39. 